\title{
Thermal and flexural properties of bagasse/cement composites
}

Marie-Ange Arsène PhD

Professor, UFR Sciences Exactes et Naturelles, Laboratoire COVACHIMM2E - EA 3592, Campus de Fouillole, Université des Antilles, Guadeloupe, France

Ketty Bilba PhD*

Assistant Professor, UFR Sciences Exactes et Naturelles, Laboratoire COVACHIM-M2E - EA 3592, Campus de Fouillole, Université des Antilles, Guadeloupe, France
Cristel Onésippe PhD

Assistant Professor, UFR Sciences Exactes et Naturelles, Laboratoire

COVACHIM-M2E - EA 3592, Campus de Fouillole, Université des Antilles, Guadeloupe, France

Loïc Rodier PhD

Postdoctoral Researcher, UFR Sciences Exactes et Naturelles, Laboratoire

COVACHIM-M2E - EA 3592, Campus de Fouillole, Université des Antilles,

Guadeloupe, France

Enhancing the sustainability, circular economy and use of by-products and renewable resources concerns a great number of researchers. Adding value to tropical vegetable resources and proposing a replacement for asbestos are challenges for chemists. Sugar cane bagasse is evaluated both as a mineral replacement and as a reinforcement in cementitious paste. In this matrix, ordinary Portland cement is partly replaced by natural pozzolan and bagasse ashes; a ternary binder is obtained. The pastes reinforced with vegetable fibers are prepared by the incorporation of untreated and pyrolyzed bagasse fibers (2-6 wt\%) in this modified matrix. The thermal conductivity and the bending strength of the composite pastes, placed in various environments (curing chamber and water), are evaluated and compared to those of composite pastes made with commercial cement and bagasse fibers, exposed to identical aging conditions. The more relevant results are obtained in the curing chamber: the composite pastes prepared with the ternary matrix conduct less heat than the commercial binder composites at $\mathbf{2 8} \mathrm{d}$, and better bending strengths are obtained with the ternary binder composites at $\mathbf{2 8}$ and $\mathbf{9 0} \mathrm{d}$, particularly with the untreated bagasse fibers.

\section{Introduction}

Guadeloupe is a French Caribbean island with a tropical climate (latitude $16^{\circ} 59^{\prime} 45^{\prime \prime}$ north, longitude $62^{\circ} 04^{\prime} 03^{\prime \prime}$ west) and where seismicity is high and hurricanes occur frequently, so the choice of construction materials takes an essential place in structure design. As the durability of construction materials is strongly related to the exposure conditions, metallic structure degradation by corrosion is one of the preoccupations of researchers.

As shown by various authors, ${ }^{1-3}$ a way to prevent structure corrosion is the use of pozzolanic materials during the preparation of pastes, mortars or concretes. These silico-aluminous materials, when they are finely crushed, ${ }^{4}$ react with the calcium hydroxide $\left(\mathrm{Ca}(\mathrm{OH})_{2}\right)$ released during cement hydration, to form products of the same chemical nature as the hydration products of cement. In Guadeloupe, cement is widely used for construction. A way to prevent the corrosion of steel framework in concrete is the partial replacement of cement by natural local pozzolan or ashes prepared from agro-industrial by-products. As indicated by Malhotra and Metha, ${ }^{5}$ using pozzolanic materials coming from vegetable, mineral or agro-industrial by-products leads to $(a)$ mechanical and physical-chemical benefits: improved mechanical strength, low permeability and strength against aggressive chemicals and thermal cracking; $(b)$ economic benefits: reduced cost of buildings with the replacement of $20-60 \%$ by mass of cement by pozzolanic materials; and $(c)$ ecological benefits: reduction of greenhouse gas (GHG) emission because of the partial replacement of cement in concrete and contribution to sustainability.

Moreover, French thermal and acoustic regulations ${ }^{6}$ expect autosufficiency and use of $50 \%$ renewable power in energy consumption by 2020 . These regulations are essentially based on the improvement of the energy performance of buildings and the reduction of air-conditioning use. Knowing that in Guadeloupe, in 2012, more than $46 \%$ of the GHG effect was due to the transformation, production and distribution of energy, ${ }^{7}$ it is important to master this production of gas. The use of vegetable fibers as insulator and reinforcement in a cementitious matrix is a way to meet the requirements of these regulations. Indeed, due to fiber porosity, low thermal and acoustic conductivities can be obtained. $^{8}$

Pozzolanic materials, as ashes coming from plant wastes, are an efficient product to improve the physical-chemical performance of a cementitious matrix, by limiting the chemical agent diffusion in the cement and improving its durability. ${ }^{1-3}$ Plant fibers can be introduced to the material in order to reduce the thermal 
conductivity of the resulting material. Those fibers are good candidates to obtain a material with interesting thermal properties due to their lumen, which appears as a cavity. ${ }^{8}$ Using the same plant to obtain an insulating sustainable material is a way to use all of the sugar cane waste.

The aim of this paper is to evaluate the influence of the chemical composition of the modified matrix - that is, the effect of the partial replacement of ordinary Portland cement by natural pozzolan (NP) and bagasse ashes (BAs) - on the thermal conductivity and the bending strength of composites containing various amounts of bagasse fibers. The measure of specific heat is also determined for the composite materials. Bagasse wastes will be used either as a mineral addition after calcination or as a reinforcement to prepare non-conventional building materials, as an attempt to add value to these vegetable residues. The samples are placed in a curing chamber or in water for short and medium durations (28 and $90 \mathrm{~d}$ ) and for long periods (180 and $360 \mathrm{~d}$ ) in order to follow both the hydration of cementitious matrices and the behavior of the natural fibers as reinforcing elements.

\section{Materials and methods}

\subsection{Materials}

Composite materials were obtained by mixing raw or pyrolyzed bagasse fibers $(0 \cdot 4-1 \mathrm{~mm}$ of thickness, $2-6 \mathrm{wt} \%$ of the dry constituents of the matrix) with either a modified ternary matrix or commercial cement. Fibers were pyrolyzed under a nitrogen gas flow $(2 \mathrm{l} / \mathrm{h}){ }^{9}$

\subsubsection{Renewable resource}

Bagasse, the fibrous solid residue left after the juice extraction from sugar cane stalk (Saccharum officinarum), is furnished by the Montebello distillery (Petit-Bourg, Guadeloupe, FWI). Sugar cane grows largely in tropical regions and can be harvested every $10-12$ months. After air-drying and oven-drying $\left(60^{\circ} \mathrm{C}\right)$, bagasse is crushed and processed in a horizontal sieve shaker (Restch, France); particles with a diameter in the range 0.4 to $1 \mathrm{~mm}$ are kept for the study.

Dried and sieved particles are separated in three parts.

- A first portion is burnt to ashes at $600^{\circ} \mathrm{C}(2 \mathrm{~h}$; Carbolite, England), which is a temperature in the range already proposed to prepare vegetable ashes ${ }^{3,10}$ and ashes with pozzolanic activity. After grinding at $500 \mathrm{rpm}$ for $2 \mathrm{~min}$ in a ball mill (Frist, France), the BAs are then used as mineral replacement for ordinary Portland cement.

- A second part is added as the raw-vegetable reinforcement in the cementitious matrix, to evaluate the influence of these bagasse fibers on the thermal properties and the flexural strength of composites.

- A third portion is pyrolyzed $\left(200^{\circ} \mathrm{C}, 2 \mathrm{~h}\right.$ under nitrogen gas flow of $21 / h)^{9}$ before its addition as vegetable-pyrolyzed reinforcement in the cementitious matrix. Moreover, authors have shown elsewhere that pyrolysis carried out in these conditions results in modified vegetable fiber/cementitious composites with better mechanical properties when compared with the corresponding untreated vegetable fiber/cementitious composites. ${ }^{11}$

\subsubsection{Matrix preparation}

The ternary matrix named ternary is a cementitious mixture of commercial Portland cement without mineral additions (CEM I $52.5 \mathrm{~N}, 80 \%$ by mass) provided by a Cruas manufactory (Calcia, France), NP (15\% by mass) from south of the volcanic region of Guadeloupe supplied by Les Sablières de Guadeloupe and BAs ( $5 \%$ by mass) prepared in the laboratory (Table 1$)$. As a result, $20 \%$ by mass of the ordinary Portland cement is replaced by NP and BAs in this study.

In order to evaluate the ternary matrix, another commercial Portland cement, named Le Classic, is used as a reference. It is a CEM II $32.5 \mathrm{~N}$ (Lafarge, Guadeloupe), containing $83 \%$ by mass of clinker and approximately $17 \%$ by mass of NP, provided by the Lafarge group, complying to AFNOR standard EN 197-1. ${ }^{12}$ It will be noted as CLA, and it is generally used to prepare mortars and concretes. In this way, the ternary matrix and the CLA present about the same amount of mineral replacement and the same NP.

\subsubsection{Composite materials}

The sheets of composite pastes were prepared following the slurry vacuum dewatering process, which stands as a crude reproduction at small scale of the Hatschek method, which itself is usually used for the industrial preparation of composite cement pastes. ${ }^{13}$ To avoid the competition for water between the cement hydration and the cellulose fiber during the preparation of the sheets of the composite cement paste, the first step was to humidify the fibers. Cement, mineral additions (NP and BAs), fibers and water were mixed for $5 \mathrm{~min}$ with an initial water/binder ratio equal to 0.8 for $5 \mathrm{~min}$, and then the mix was placed in a casting box $(190 \mathrm{~mm} \times 200 \mathrm{~mm})$. The water/binder ratio was calculated as follows.

1. $\frac{\left(m_{\mathrm{i}}-m_{\mathrm{f}}\right)}{[\operatorname{binder}(\text { cement }+\mathrm{NP}+\text { ashes })]}$

where $m_{\mathrm{i}}$ is the initial mass of introduced water and $m_{\mathrm{f}}$ is the mass of water after the dewatering process. This casting box was

\begin{tabular}{lcccc} 
& \multicolumn{4}{c}{ Material content by mass: \% } \\
\cline { 2 - 5 } Matrix & CEM I 52.5 N & CEM II 32.5 N (CLA) & NP & BAs \\
Ternary & 80 & 0 & 15 & 5 \\
CLA & 0 & 100 & 0 & 0 \\
\hline
\end{tabular}

Table 1. Matrix formulations 
placed under a vacuum for $10 \mathrm{~min}$ to remove excess water. The sheets were pressed for $5 \mathrm{~min}$ at $0.5 \mathrm{MPa}$. Randomly oriented fiber composite sheets $(190 \mathrm{~mm} \times 200 \mathrm{~mm}, 11-16 \mathrm{~mm}$ thick according to the amount of introduced fibers) were obtained and characterized. For example, in the case of composites with $6 \mathrm{wt} \%$ composites, the water/binder ratio was around 0.55 after the production of sheets. To compare the properties of ternary matrix composites to the composites prepared with commercial cement containing NP (CLA), composites including $2-6 \%$ by mass of raw and pyrolyzed bagasse fibers were prepared with the same method as the composites made with a ternary matrix.

The method used to name the sheets of composites is as follows: the name of the matrix (ternary or CLA) is followed by $x \mathrm{~B}$ or $x \mathrm{P}$, corresponding respectively to the amount by mass of raw or pyrolyzed bagasse fibers, with $x=2,4,6 \mathrm{wt} \%$.

\subsection{Methods}

For aging, the composite pastes were placed in a curing chamber $\left(23^{\circ} \mathrm{C}, 50 \%\right.$ relative humidity $\left.(\mathrm{RH})\right)$ as the standard curing conditions or immersed in water at 23 and $40^{\circ} \mathrm{C}$ as an accelerated aging process. The samples were placed in the standard curing conditions for 28 and $90 \mathrm{~d}$ and in water for 180 and $360 \mathrm{~d}$, to simulate the behavior of the materials in tropical weather conditions after a few years of rainy season. After curing in water, the samples were dried at $23^{\circ} \mathrm{C}$ and $50 \% \mathrm{RH}$ until a constant mass was reached, before the thermal and mechanical tests.

The chemical compositions of NP, BAs and commercial cements were determined by X-ray semiquantitative fluorescence in the Service Central d'Analyses du Centre National de la Recherche Scientifique, Lyon (Table 2).

The X-ray diffraction spectra of NP and ashes were carried out by Service Rayons X of Institut de Chimie de la Matière Condensée de Bordeaux (Figure 1).
The particle size distributions of cement, NP and ashes were determined in ethanol, with a Cilas granulometer (Cilas, France; Table 3). A Blaine permeabilimeter allowed the determination of the specific surfaces of samples (Table 3 ).

The apparent porosity of the composite materials was determined according to the ASTM C 948 standard. ${ }^{14}$

The thermal and flexural characteristics of the samples, either the controls without fiber or the composite materials, were determined in laboratory conditions $\left(23^{\circ} \mathrm{C}, 50 \% \mathrm{RH}\right)$.

The hot-wire method allowed measurement of the thermal conductivity of samples. The equipment used, a CT-Mètre developed by Le Centre Scientifique et Technique du Bâtiment, is in accordance with the NF EN 993-15 standard. ${ }^{15}$ The thermal conductivity of the material was measured by following the temperature with a thermocouple placed close to a resistive wire. The probe, made of a resistive wire and a thermocouple in an insulating support, was placed between two identical samples of the same material to be characterized. The equipment commercialized by Controlab (France) performs in the following working conditions: the thermal conductivity of the samples varying between 0.02 and $5 \mathrm{~W} /(\mathrm{m} \mathrm{K})$, the temperature ranging between 20 and $80^{\circ} \mathrm{C}$ and the minimal dimensions of the sample as $80 \mathrm{~mm} \times 40 \mathrm{~mm} \times$ a few millimeters thick. The specimens' dimensions were $120 \mathrm{~mm} \times$ $14 \mathrm{~mm} \times 11-16 \mathrm{~mm}$ thick, according to the amount of introduced fibers. For each formulation, the measurements were repeated six times on the same day, in laboratory conditions $\left(23^{\circ} \mathrm{C}, 50 \% \mathrm{RH}\right)$, in order to evaluate the standard deviation.

The specimens were weighted and placed in a normalized, cleaned and dried measuring cell of an isothermal calorimeter C80 (Setaram, France), to measure the specific heat $\left(C_{\mathrm{p}}\right)$ of the samples at $30^{\circ} \mathrm{C}$. After thermal equilibrium, the following thermal profile was monitored: $(a)$ isotherm at $30^{\circ} \mathrm{C}$ for $15 \mathrm{~min}$, (b) increase in temperature from $30^{\circ} \mathrm{C}$ to $80^{\circ} \mathrm{C}$ at $0 \cdot 2^{\circ} \mathrm{C} / \mathrm{min}$,

\begin{tabular}{lrrrr} 
& \multicolumn{5}{c}{ Content by mass: \% } \\
\cline { 2 - 5 } Constituent & BA & NP & CEM I 52.5 N & CEM II 32.5 N (CLA) \\
Silicon dioxide & 57.7 & 43.54 & 21.45 & 24.66 \\
Iron (III) oxide & 3.22 & 7.96 & 0.22 & 5.04 \\
Aluminum oxide & 6.66 & 18.49 & 4.08 & 7.06 \\
Calcium oxide & 4.15 & 12.48 & 65.05 & 55.70 \\
Sodium oxide $\left(\mathrm{Na}_{2} \mathrm{O}\right)$ & 0.26 & 2.05 & 0.06 & 0.28 \\
Potassium oxide & 13.63 & 0.39 & 0.20 & 0.38 \\
Magnesium oxide & 4.16 & 4.56 & 0.49 & 1.60 \\
Chlorine $(\mathrm{Cl})$ & 0.84 & - & - & - \\
Loss on ignition & 0.17 & 0.86 & 1.45 & - \\
Humidity & 1.63 & 2.72 & - & - \\
Silicon dioxide + iron (III) oxide + aluminum oxide & 67.58 & 69.99 & - & - \\
\hline
\end{tabular}

Table 2. Chemical compositions of BAs, NP and commercial cements (CEM I 52.5N, CLA) 


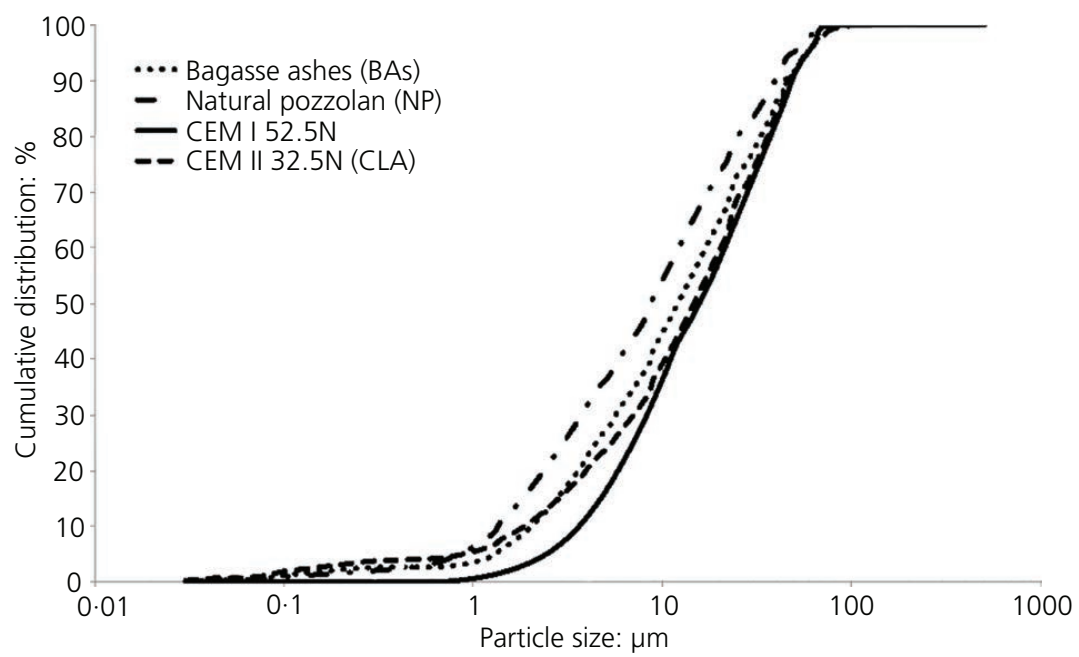

Figure 1. Cumulative particles size distributions of NP, BAs, CEM I $52.5 \mathrm{~N}$ and CEM $\| 32.5 \mathrm{~N}$ (CLA)

\begin{tabular}{lccc} 
Material & Specific density: $\mathbf{~} / \mathbf{c m}^{\mathbf{3}}$ & Median size particles $\mathbf{d}_{\mathbf{5 0}}: \boldsymbol{\mu m}$ & Specific surface $\mathbf{a r e a : ~} \mathbf{c m}^{\mathbf{2}} / \mathbf{g}$ \\
BA & $2 \cdot 30 \pm 0.02$ & 13.05 & $11866 \pm 258$ \\
NP & $2 \cdot 83 \pm 0.03$ & 9.50 & $6487 \pm 114$ \\
CEM I 52.5N & $3.08^{\mathrm{a}}$ & $15 \cdot 70$ & $4200^{\mathrm{a}}$ \\
CLA & $3.07^{\mathrm{a}}$ & $15 \cdot 60$ & $3190^{\mathrm{a}}$ \\
\hline
\end{tabular}

a Supplier data

Table 3. Some physical properties of the studied materials

(c) decrease in temperature in the range $80-30^{\circ} \mathrm{C}$ at $1{ }^{\circ} \mathrm{C} / \mathrm{min}$ and (d) isotherm at $30^{\circ} \mathrm{C}$ for $16 \mathrm{~h}$. A blank (control) test without the sample was performed with the same monitored thermal profile. The specific heat was calculated according to the following equation.

$$
\text { 2. } C_{\mathrm{p}}=\frac{A_{\mathrm{s}}-A_{\mathrm{b}}}{m_{\mathrm{s}} \times \beta}
$$

where $C_{\mathrm{p}}$ is the specific heat $(\mathrm{J} / \mathrm{kg} \mathrm{K}), A_{\mathrm{s}}$ and $A_{\mathrm{b}}$ are the ranges of the heat measured for the sample and the blank respectively (W), $m_{\mathrm{s}}$ is the mass of sample $(\mathrm{g})$ and $\beta$ is the heating speed $(\mathrm{K} / \mathrm{s})$. A polynomial regression can be obtained from the experimental data, in order to extrapolate the specific heat to a temperature different from the studied range.

The flexural strength of the materials was determined by the threepoint bending test, with a bicolumn universal machine (Instron, France) with a cell of $500 \mathrm{~N}$ and a speed load of $0.5 \mathrm{~mm} / \mathrm{min}$. The span was $100 \mathrm{~mm}$, and the specimen dimensions were $120 \mathrm{~mm} \times$ $35 \mathrm{~mm}$ with thickness between 11 and $16 \mathrm{~mm}$. Four samples of each formulation were tested in laboratory conditions.

\section{Results and discussion}

\subsection{Raw materials for ternary matrix}

\subsubsection{Chemical composition}

The chemical compositions of BAs, NP and commercial cements (CEM I $52.5 \mathrm{~N}$, CLA) are presented in Table 2.

The BA is composed of oxides of silicon (silicon dioxide $\left(\mathrm{SiO}_{2}\right)$ ), potassium (potassium oxide $\left(\mathrm{K}_{2} \mathrm{O}\right)$ ), aluminum (aluminum oxide $\left(\mathrm{Al}_{2} \mathrm{O}_{3}\right)$ ), magnesium (magnesium oxide $(\mathrm{MgO})$ ), calcium (calcium oxide $(\mathrm{CaO})$ ) and iron (iron (III) oxide $\left(\mathrm{Fe}_{2} \mathrm{O}_{3}\right)$ ); this composition is related to the place where sugar cane plants were collected, as shown by Ganesan et al., ${ }^{3}$ Suliman et $a .^{16}$ and Cordeiro et al. ${ }^{10}$ Some chlorine is observed in the $\mathrm{BA}$, and some potassium chloride $(\mathrm{KCl})$ was confirmed on $\mathrm{X}$-ray diffraction spectra; this is due to the fertilizers present in the soil.

In the case of NP, silicon dioxide, aluminum oxide, calcium oxide and iron (III) oxide are the major components. Day et al. ${ }^{17}$ proposed that the chemical composition of the pozzolan is due to the mineral components of soil, which depend on its geological origin and on volcanic eruptions that produce it. 
The total amount of silicon, aluminum and iron oxides (silicon dioxide + iron (III) oxide + aluminum oxide) is equal to $67 \cdot 58 \%$ for BA and $69 \cdot 99 \%$ by mass for NP. These values are slightly inferior but close to the one proposed by the ASTM C 618 norm (which is a minimum of $70 \%)^{18}$ which specifies the chemical requirements for coal fly ash and raw or calcinated NP for use in concrete. Only NP fulfills this chemical requirement. Nevertheless, although BAs do not present the required minimal content of silicon dioxide + iron (III) oxide + aluminum oxide, they have already shown pozzolanic activity. ${ }^{19}$ The total content of silicon dioxide + iron (III) oxide + aluminum oxide determined in this study is superior to that obtained by Cordeiro et al. ${ }^{19}$ and inferior to that proposed by Ganesan et al. ${ }^{3}$ For NP, the silicon dioxide + iron (III) oxide + aluminum oxide amount is inferior to the value reported by Senhadji et al. ${ }^{20}$ and Mouli and Khelafi ${ }^{21}$ but superior to the content calculated by Shannag. ${ }^{22}$ These observations show that the BAs and the NP used in the present work are valid as pozzolanic materials when compared to literature.

The loss on ignition of BA shows that $600^{\circ} \mathrm{C}$ is a sufficient temperature to remove volatile and not-burnt compounds, which can have a detrimental effect on the durability of cementitious material. ${ }^{23}$ A small loss of ignition of pozzolan is interpreted as low organic matter. The ASTM C 618 standard $^{18}$ fixes a maximal loss on ignition of $10 \%$ for raw and calcinated pozzolan and ashes. So BA and NP satisfy the ASTM C 618 standard.

CEM I $52.5 \mathrm{~N}$ is mainly composed of calcium oxide, silicon dioxide and aluminum oxide. The loss on ignition of this cement is close to $2 \%$; it is superior to the loss on ignition values for BA and NP perhaps because of a premature hydration of the mineral phases of the clinker and/or the hydration of calcium oxide, which leads to calcium hydroxide formation. ${ }^{24}$

For BA and NP, humidity values comply with the ASTM C 618 standard, as they are lower than $3 \%$ by mass.

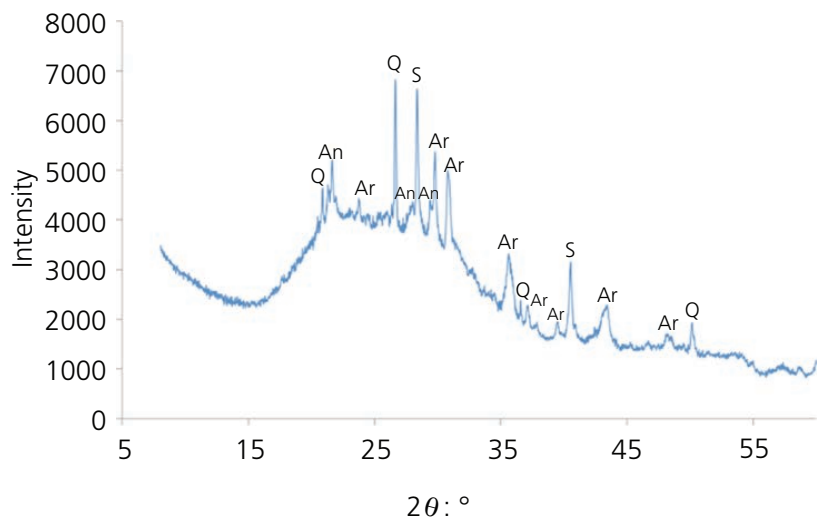

(a)
So the chemical composition, the loss on ignition and the humidity of the NP fulfill the requirements of the ASTM C 618 standard. ${ }^{18}$ BAs also fulfill those conditions except for chemical composition, but show pozzolanic activity. ${ }^{19}$

The X-ray diffraction spectra of BAs and NP are shown in Figure 2.

The spectrum of BA shows, at $2 \theta$ between $20^{\circ}$ and $40^{\circ}$, an amorphous phase $\mathrm{e}^{24,25}$ and the crystallized compounds quartz $\left(\mathrm{SiO}_{2}\right)$, marked Q; potassium chloride, marked $\mathrm{S}$; anorthite $\left(\mathrm{CaAl}_{2} \mathrm{Si}_{2} \mathrm{O}_{8}\right)$, marked $\mathrm{An}$; and potassium sulfate $\left(\mathrm{K}_{2} \mathrm{SO}_{4}\right)$, marked Ar. The presence of the amorphous phase suggests a future pozzolanic activity. ${ }^{25,26}$

\subsubsection{Particle size distribution, specific surface and helium density}

The particle size distributions of NP, BAs and cements are presented in Figure 1.

The curves have a similar shape but the curve of the cement is shifted to greater particle sizes. Some differences can be seen, in the following ranges.

- $0 \cdot 3-40 \mu \mathrm{m} ; \mathrm{BA}$ and NP have more particles of smaller sizes than cement.

- $0 \cdot 08-20 \mu \mathrm{m}$; NP presents more particles of smaller sizes than BAs.

The median size particles $\left(d_{50}\right.$, Table 3$)$ of NP, BA and cements (CEM I $52.5 \mathrm{~N}$ and CLA) are 9.50, 13.05, 15.70 and $15.60 \mu \mathrm{m}$ respectively; these values are in accordance with first observations.

The specific surface areas of the three components (BA, NP, CEM I $52.5 \mathrm{~N}$ ) of the ternary matrix are presented in Table 3 . The specific surfaces areas of BA and NP are higher than that of

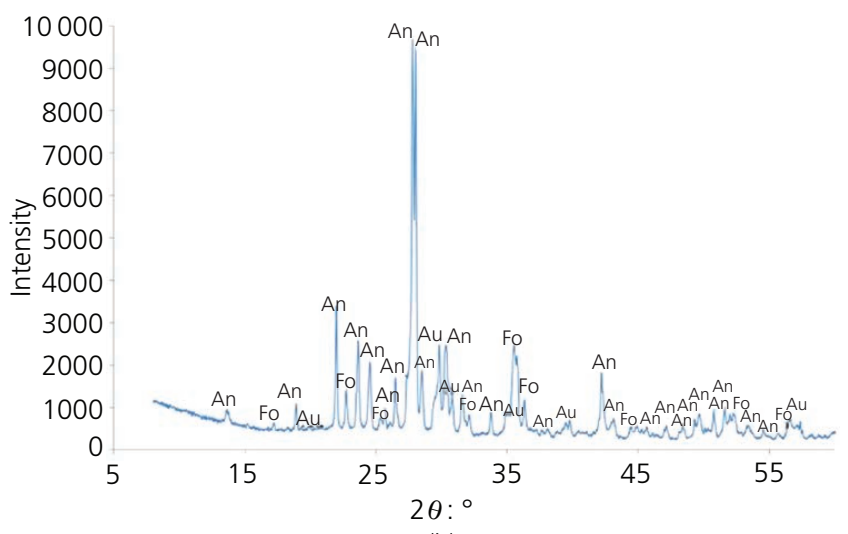

(b)

Figure 2. X-ray diffraction spectra of (a) BAs and (b) NP, with An: anorthite, Ar: potassium sulfate, $\mathrm{Au}: \mathrm{Ca}(\mathrm{Mg}, \mathrm{Fe}, \mathrm{Al})(\mathrm{Si}, \mathrm{Al})_{2} \mathrm{O}_{6}, \mathrm{Fo}$ : $\mathrm{Mg}_{1 \cdot 46} \mathrm{Fe}_{0.54} \mathrm{SiO}_{4}$, Q: silicon dioxide, S: potassium chloride 
cement; this could lead to an increase in water demand. ${ }^{27}$ The specific surface area of BA is similar to that determined by Cordeiro et al. $\left(11887 \mathrm{~cm}^{2} / \mathrm{g}\right){ }^{19}$

The specific densities of BA and NP determined by helium picnometry are indicated in Table 3; supplier data are listed for the cements. They are equal to $2 \cdot 83,2 \cdot 30,3.08$ and $3 \cdot 07 \mathrm{~g} / \mathrm{cm}^{3}$. The standard deviations obtained for NP and BA are around $1 \%$ of the mean value, which is lower than the $5 \%$ specified by the ASTM C 618 standard. ${ }^{18}$ So the replacement of cement by NP and/or BA could result in lighter building materials than cement alone. Another advantage to introducing NP and/or BA in cement is the reduction of transport cost during building construction.

\subsection{Composite materials}

In order to evaluate the interest of the ternary matrix, the preparation and characterization of the composite pastes are proposed. The properties of these composites are compared to the characteristics of composites prepared with the CLA commercial matrix (CEM II $32.5 \mathrm{~N}$ ).

\subsubsection{Influence of curing on properties of composites \\ 3.2.1.1 THERMAL BEHAVIOR}

The thermal conductivities of the prepared composites, after 28 and $90 \mathrm{~d}$ of aging in a curing chamber, are presented in Figure 3.

The ternary matrix conducts heat better than the commercial CLA; its thermal conductivity $\lambda$ being higher than that of the CLA, no matter the age of the materials. But when adding bagasse fibers, the thermal conductivity of composites is always lower than that of the matrix without fiber, especially in the case of composites made with the ternary matrix. Indeed, when drawing lines $\lambda=f$ (amount of fibers), the slopes of the ternary binder composite

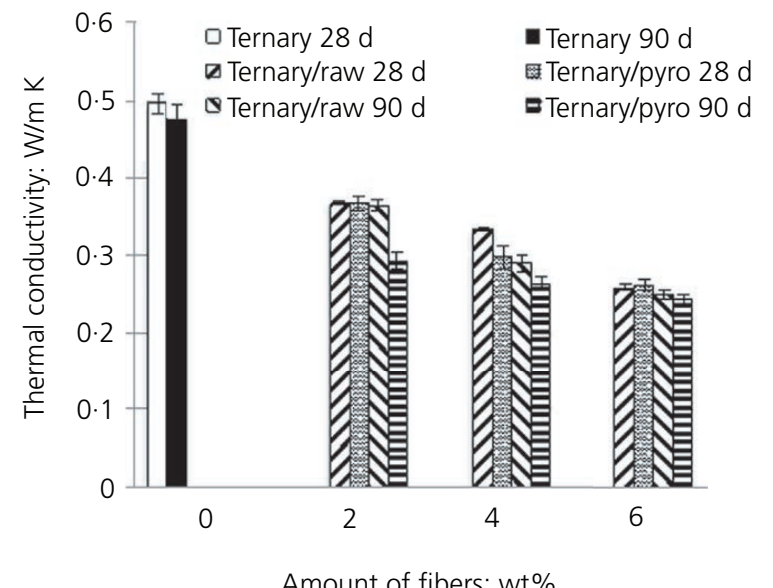

(a) linear regressions are more negative than those of the CLA-based composites. For example, for the ternary binder composites, the equation is $\lambda=-(0.0373 \times$ amount $)+0.4755$, while for CLAbased composites, it is $\lambda=-(0.0301 \times$ amount $)+0.4184$, after $28 \mathrm{~d}$ for composites prepared with raw fibers. Considering only the ternary binder composites, more negative slopes are observed for the composites prepared with pyrolyzed bagasse fibers whatever the age, but the slopes of the lines of the composites prepared with raw and pyrolyzed fibers are all in the same order of magnitude; so the pyrolysis of the fibers does not influence the thermal conductivity of the composites, in this piece of work.

The decrease in the thermal conductivity of the composites with different amounts of fibers is more noticeable for $6 \%$ by mass when compared to the reference. The composite conductivity reaches a quasi-plateau with age and amount of fibers depending on the matrix. For ternary composites, the stabilization seems to be reached for $6 \%$ by mass, whatever the age and the fiber treatment, for the present experiment, the duration and the thermal treatment of fibers. While for commercial composites, the stabilization is noted after $90 \mathrm{~d}$, especially for $6 \%$ by mass. The conductivities of the composites made with commercial cement are, at this age, higher than the corresponding composites made with the ternary matrix.

When drawing the thermal conductivity $\lambda$ against the porosity, the curves of all composite samples follow a linear shape, as $\lambda=(a \times$ porosity) $+b$. The values of $a$ and $b$ are shown in Table 4 . The thermal conductivity decreases with porosity, as expected. ${ }^{8}$ This decrease is more marked in the case of the ternary composites, especially after $90 \mathrm{~d}$ of curing, and also in the case of composite pastes prepared with pyrolyzed fibers. The porosity of the composite materials increasing with time may be due to the

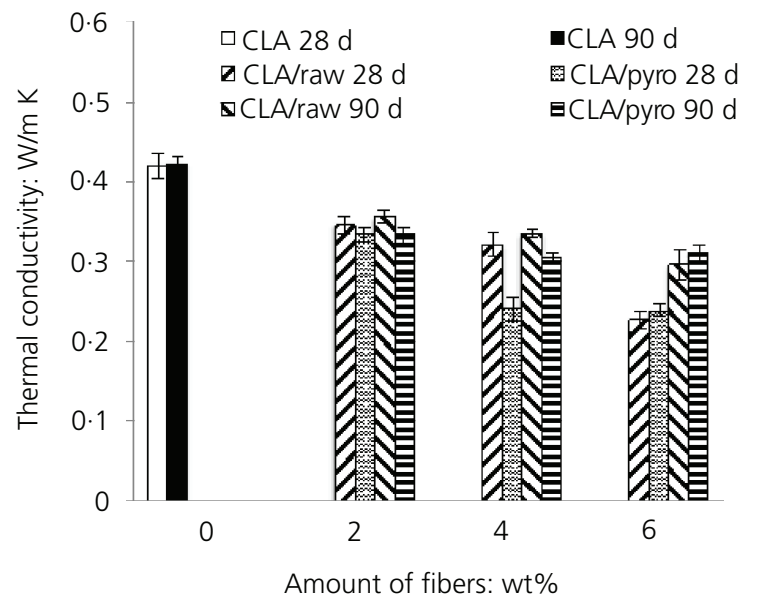

(b)

Figure 3. Thermal conductivity of composites made of (a) ternary matrix and (b) commercial matrix, with raw and pyrolyzed bagasse fibers 
release of water present in humidified fibers, leading to the retraction of fibers and pore creation.

\subsubsection{SPECIFIC HEAT}

The specific heat values for the matrix without fiber (ternary and CLA) and the composites prepared with raw and pyrolyzed bagasse fibers ( $2 \%$ by mass and $6 \%$ by mass) after $28 \mathrm{~d}$ of aging in the curing chamber are presented in Table 5.

After $28 \mathrm{~d}$ for all composite materials, taking into account the standard deviations, the specific heats are of the same order of magnitude, whatever the matrix and the amount of added fibers; so the chemical composition of the matrix has no effect on the specific heat. The specific heat $\left(C_{\mathrm{p}}\right)$ and the thermal conductivity $(\lambda)$ are related, ${ }^{28}$ according to $\lambda=$ diffusivity $\times C_{\mathrm{p}}$ density. On one hand, the thermal conductivity varies as a function of the matrix, the amount and the treatment of the fibers as shown in section 3.2.1.1, and on the other hand, the specific heat is quasi-constant, that is to say that diffusivity $\times$ density changes with those parameters. Indeed Bejaoui and Bary, ${ }^{29}$ in a modeling study of the link between microstructure and effective diffusivity of cement paste, proposed that the diffusivity of calcium silicate hydrates $\left((\mathrm{CaO})_{x}\left(\mathrm{SiO}_{4}\right)_{y}\right.$ $\left(\mathrm{H}_{2} \mathrm{O}\right)_{z}$ or $\mathrm{CSHs}$ ) produced during the cementitious matrix hydration depends on the density of these products.

When adding fibers, the porosity increases, and the $C_{\mathrm{p}}$ remains constant, showing that the porosity does not influence $C_{\mathrm{p}}$. The variations of the thermal conductivity seem to be related to porosity variations. Since $\lambda=$ diffusivity $\times C_{\mathrm{p}} \times$ density and $\lambda$ decreases, it appears that diffusivity $\times$ density decreases. As diffusivity is the ability of a material to transmit quickly a variation of heat, the ternary composites are insulating materials.

As ternary binder composites store and conduct less heat than CLA-based composites, the composites made with the ternary matrix present better insulating properties than the composites made with commercial CLA matrix at $28 \mathrm{~d}$, after being in the curing chamber.

\subsubsection{BENDING STRENGTH}

After 28 and $90 \mathrm{~d}$ of curing, the bending strengths of the composites prepared with the ternary matrix are presented in

\begin{tabular}{|c|c|c|c|c|c|c|c|c|}
\hline \multirow{2}{*}{ Composite materials } & \multicolumn{4}{|c|}{$28 \mathrm{~d}$} & \multicolumn{4}{|c|}{$90 \mathrm{~d}$} \\
\hline & Ternary B & Ternary $\mathbf{P}$ & CLA B & CLA P & Ternary B & Ternary $\mathbf{P}$ & CLA B & CLA P \\
\hline$a$ & -0.0057 & -0.0074 & -0.0043 & -0.0068 & -0.0062 & -0.0079 & -0.0035 & -0.0032 \\
\hline$b$ & 0.7008 & 0.7534 & 0.5497 & 0.6320 & 0.7444 & 0.7992 & 0.5232 & 0.75107 \\
\hline Amount of fibers: wt\% & \multicolumn{8}{|c|}{ Porosity: \% } \\
\hline 0 & $37 \cdot 87$ & $37 \cdot 87$ & 32.77 & $32 \cdot 27$ & $43 \cdot 52$ & $43 \cdot 52$ & $30 \cdot 17$ & $30 \cdot 17$ \\
\hline 2 & 54.71 & 52.64 & 46.09 & $43 \cdot 54$ & $61 \cdot 78$ & 59.02 & 44.73 & 43.65 \\
\hline 4 & $64 \cdot 29$ & 55.93 & $51 \cdot 27$ & 54.40 & 73.67 & $66 \cdot 87$ & $55 \cdot 13$ & $52 \cdot 83$ \\
\hline 6 & 78.61 & $70 \cdot 37$ & $76 \cdot 16$ & $60 \cdot 61$ & $79 \cdot 81$ & $73 \cdot 23$ & $65 \cdot 29$ & 65.88 \\
\hline
\end{tabular}

Ternary and CLA identify the matrix; $B$ for untreated fibers and $P$ for pyrolyzed fibers

Table 4. Porosities of composite pastes

\begin{tabular}{|c|c|c|c|c|c|}
\hline \multirow{2}{*}{ Environment } & \multicolumn{3}{|c|}{$28 \mathrm{~d}$} & \multicolumn{2}{|r|}{$180 \mathrm{~d}$} \\
\hline & Material & Specific heat: J/(g K) & Porosity: \% & Material & Specific heat: J/(g K) \\
\hline \multirow[t]{6}{*}{ Curing chamber $\left(23^{\circ} \mathrm{C}, 50 \% \mathrm{RH}\right)$} & Ternary & $1 \cdot 14 \pm 0.08$ & $37 \cdot 87$ & & \\
\hline & Ternary 2B & $1 \cdot 19 \pm 0.04$ & $54 \cdot 71$ & Ternary 2B & $1 \cdot 12 \pm 0 \cdot 04$ \\
\hline & Ternary 6B & $1 \cdot 06 \pm 0.21$ & $78 \cdot 61$ & Ternary 6B & $1 \cdot 11 \pm 0.01$ \\
\hline & CLA & $1 \cdot 12 \pm 0.02$ & $32 \cdot 27$ & & \\
\hline & CLA 2B & $1 \cdot 14 \pm 0.01$ & $46 \cdot 09$ & Ternary 2P & $1 \cdot 12 \pm 0.01$ \\
\hline & CLA 6B & $1.13 \pm 0.03$ & $76 \cdot 16$ & Ternary 6P & $1.12 \pm 0.02$ \\
\hline \multirow[t]{4}{*}{ Water at $23^{\circ} \mathrm{C}$} & & & & Ternary 2B & $1.47 \pm 0.03$ \\
\hline & & & & Ternary 6B & $1.52 \pm 0.06$ \\
\hline & & & & Ternary 2P & $1.50 \pm 0.01$ \\
\hline & & & & Ternary 6P & $1.44 \pm 0.02$ \\
\hline
\end{tabular}

Table 5. Specific heat of composite materials made of ternary matrix or commercial matrix, and raw or pyrolyzed bagasse fibers, placed in different environments 
Figure 4(a), while those composites made with commercial cement CLA are presented in Figure 4(b).

Adding fibers leads to reduced bending strengths of the composites for both matrices, whatever the age and the fiber pretreatment. This behavior has already been observed by Arsène et al. ${ }^{11}$ in the case of composites prepared with chemically treated (sulfuric acid $5 \%$ by mass) bagasse fibers, and they attributed this to the lack of adhesion between the fibers and the matrix and a different void entrapment due to the fiber treatment. In addition, the composite pads were pressed at $0.5 \mathrm{MPa}$, which is six to ten times lower than the pressure proposed by Savastano et al., ${ }^{13}$ leading to the presence of more porosity.

In the case of raw bagasse fibers, when comparing ternary binder composites and CLA-based composites to their corresponding controls, for example, at $28 \mathrm{~d}$ and two different weight percentages of raw fibers, the decrease in the bending strength is equal to 1.31 for the first one and 2.61 for the second one. Thus, the decrease in the bending strength is always higher for the CLA-based composites than for the ternary binder composites, in the case of raw fibers, whatever the age and the amount of added fibers; no trend is noted for composites made of pyrolyzed fibers. This shows that either the chemical composition of the matrix, porosity or fiber/matrix adhesion influences the flexural strength of the materials. The porosity accessible to water, determined according to ASTM C $948-2009,{ }^{14,30}$ is always higher in ternary binder composites than in CLA-based composites case, which is not the expected behavior. It has to be noted that it is the porosity accessible to water that is measured and not the total one.

At $28 \mathrm{~d}$ and for $2 \%$ by mass of fibers, when comparing ternary binder composites with raw and pyrolyzed fibers to its control, the bending strength decreases by a factor equal to 1.31 in the case of raw fibers/ternary composites and 2.65 for pyrolyzed fibers/ternary composites. For $2 \mathrm{wt} \%$ of fibers, the lowest decrease is noted in the ternary composites containing raw fibers showing that raw fibers are less degraded in the presence of the ternary matrix; this is probably because there is less calcium hydroxide - which contributes to the mineralization of fibers and reduces their mechanical properties - produced in the presence of the ternary matrix. Indeed Chapelle tests, which allow the quantification of the amount of lime fixed by a material, carried out on BAs and NP have shown that BA fixes $352 \mathrm{mg}$ of calcium oxide per gram of material and NP absorbs $290 \mathrm{mg}$ of calcium oxide per gram of materials. ${ }^{29}$ BAs will react with more calcium hydroxide than NP; so the amount of calcium hydroxide will be lower in the presence of the ternary matrix than in the presence of commercial cement, the degradation of raw fibers will slow down and the quantity of formed calcium silicate hydrates responsible for the high compressive strength of cement will also be reduced. ${ }^{30} \mathrm{CSHs}$ are produced by the hydration of mineralogical phases of cement ( 2 calcium oxide), silicon dioxide) as dicalcium silicate $\left(\mathrm{C}_{2} \mathrm{~S}\right)$ and (3(calcium oxide), silicon dioxide) as tricalcium silicate $\left(\mathrm{C}_{3} \mathrm{~S}\right)$ ). BA reduces the reactivity of the matrix toward the fibers and/or favors the formation of $\mathrm{CSH}$; it acts as a nucleation point for the $\mathrm{CSH}$. In the ternary matrix due to the presence of three constituents (cement, NP, BA), the germination spots are more numerous than in the CLA, which contains only two constituents. The constituents of the ternary matrix present smaller median size particles $\left(d_{50}\right.$; Table 3$)$ than CLA $\left(d_{50}=15 \cdot 60 \mu \mathrm{m}\right){ }^{30}$ the particles of the ternary matrix will react faster than those of the CLA for identical chemical nature.

In CLA composites, the amount of fibers influences more or less the bending strength, according to standard deviation; for example, in the CLA 2B case, the bending strength is equal to $2.44 \pm 0.44 \mathrm{MPa}$, and for CLA $6 \mathrm{~B}$, it is $1.85 \pm 0.31 \mathrm{MPa}$. In CLA composites, the optimal amounts of fibers leading to high strengths are around $2-4 \%$ by mass for raw fibers, while for pyrolyzed fibers, the optimal content is noted for $2 \mathrm{wt} \%$. Arsène

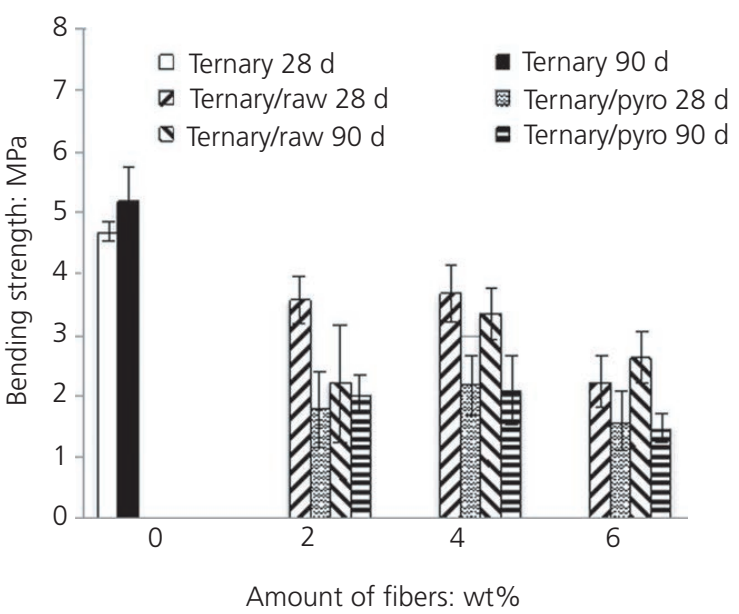

(a)

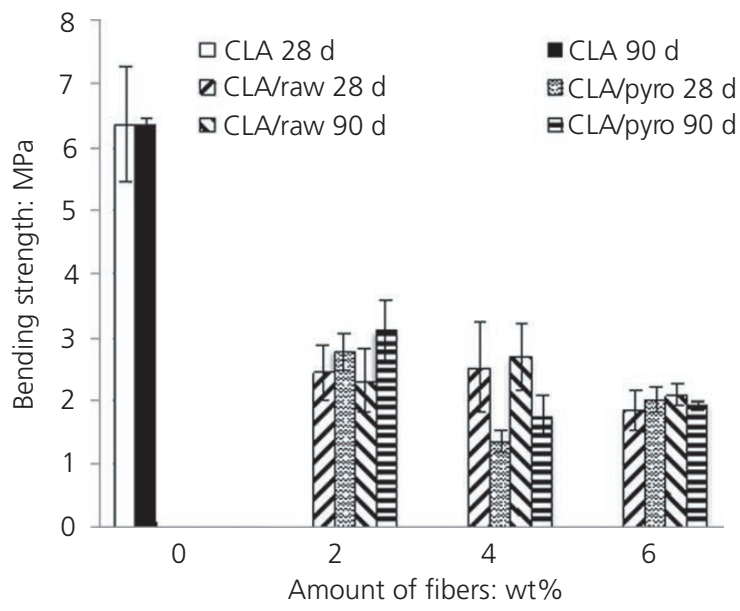

(b)

Figure 4. Bending strength of materials placed in the curing chamber 
et al. ${ }^{11}$ have already observed this optimal content for pyrolyzed fibers in a commercial matrix. In the ternary matrix, the decrease in the bending strength is observed for increasing amounts of pyrolyzed fibers; this maybe due to low fiber/matrix adhesion; in this case, crack propagation is faster.

As the bending strength in CLA composites decreases from $2 \%$ by mass of fibers and that of ternary composites decreases for higher amounts ( $4-6 \%$ by mass), more fibrous matter is necessary in the case of ternary matrix to damage the bending strength.

Composites are porous, so the bending strengths decrease. As the porosity of ternary composites is higher than the porosity of CLA composites (Table 5), their bending strengths are lower than those of CLA composites, except with raw fibers. The porosity of the composite materials increases with the amount of fibers, but it is lower in the case of the composite prepared with pyrolyzed fibers when comparing with the corresponding composite with raw fibers. Even if the porosity of the ternary composites made with pyrolyzed fibers is lower than that of the ternary composites made with raw fibers, the bending strengths of the ternary-pyrolyzed composites are low, showing that the reactivity between cement, ashes and NP is not good.

The mechanical behavior of the composite materials is due to cement hydration: thermodynamical and kinetic aspects, amounts of hydration products as CSH and presence and amount of porosity. At this stage, the ternary matrix is being less alkaline toward the raw bagasse fibers than the commercial CLA; this shows that when using a ternary matrix, pyrolysis of fibers is not necessary; the absence of pyrolysis will allow energy and nitrogen gas savings.

\subsubsection{Influence of aging environment on properties of composites}

In order to follow the evaluation of composites made with ternary matrix, their thermal conductivities, specific heats and flexural strengths were determined after exposure in water at 23 and $40^{\circ} \mathrm{C}$.

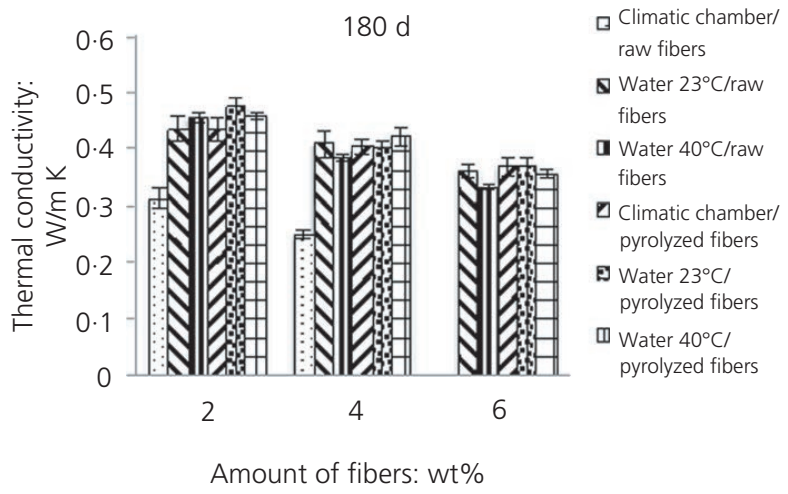

(a)

Figure 5. Thermal conductivity of bagasse fibers/ternary composites placed in various environments after (a) 180 and (b) $360 \mathrm{~d}$ of curing

\subsubsection{THERMAL CONDUCTIVITY}

The thermal conductivities of the studied materials, after 180 and $360 \mathrm{~d}$ of curing in water, are presented in Figure 5.

First, when fibers are added to the cementitious matrices, the thermal conductivities $\lambda$ of the resulting composites decrease with the increasing amount of fibers as already shown in the curing chamber whatever the age; it is known that $\lambda$ was around $0.47 \mathrm{~W} /(\mathrm{m} \mathrm{K})$ at $90 \mathrm{~d}$ for the ternary matrix without fiber. This behavior, as explained by Khedari et al. ${ }^{8}$ is due to the growth of porosity when adding fibers in the composite materials. Rodier et $a l .{ }^{28}$ have effectively shown an increase in the total porosity accessible to water when adding fibers - for example, after $180 \mathrm{~d}$ in the case of raw fibers/ternary composites, a variation of porosity with the amount of fibers is as follows: porosity $=3 x(\%$ fibers) $+45 \cdot 33$; the same trends are noted for the ternary composites prepared with pyrolyzed fibers and for $360 \mathrm{~d}$ of curing, and the highest porosity is observed for $6 \mathrm{wt} \% /$ ternary composite, which exhibits the lowest thermal conductivity.

After $180 \mathrm{~d}$ of curing, the only sample that presents a different thermal conductivity, a lower one, is the ternary composite with raw fibers placed in the curing chamber, all the other samples exhibit $\lambda$ of the same order of magnitude, while after $360 \mathrm{~d}$, both ternary composites made with either raw and pyrolyzed fibers, and placed in the curing chamber, present the lowest thermal conductivities. More pyrolysis of fibers does not seem to have a significant effect on the thermal conductivity, taking into account the standard deviations, the thermal conductivities being of same order of magnitude. Moreover, the temperature of water does not have an influence on the thermal conductivities according to standard deviations.

The thermal conductivity of materials is related to their porosities. ${ }^{8}$ Nevertheless, the porosity accessible to water does not totally explain the observed behaviors; the authors also have to consider the porosity not accessible to water, due to unconnected

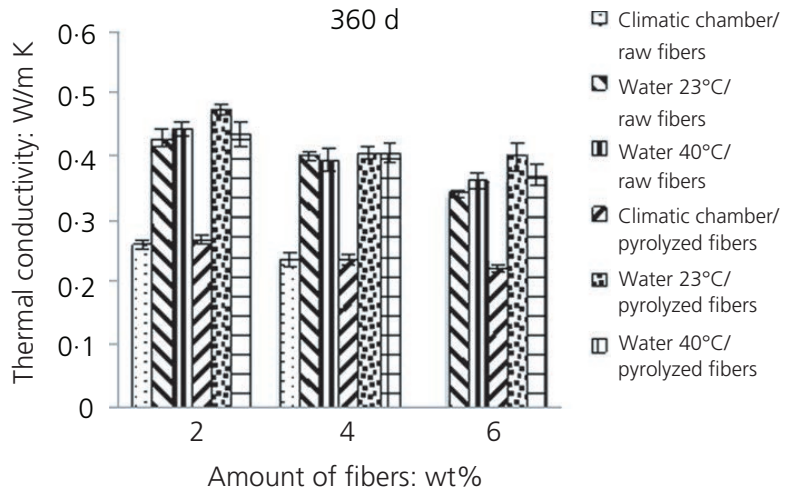

(b) 
pores. ${ }^{31}$ If the observed behavior at 28 and $90 \mathrm{~d}$ went on, the thermal conductivities of ternary composites should be inferior to that of CLA composites, which were not measured at this time.

Ternary composites, made with $2 \%$ by mass of bagasse fibers placed in water exhibit thermal conductivities of the same order of magnitude as the CLA matrix without fiber. When the amount of fibers increases, $\lambda$ decreases for ternary composites; this shows that even after aging in water, the ternary composites are still being competitive from a thermal conductivity point of view, when compared to the CLA without fiber.

\subsubsection{SPECIFIC HEAT}

The specific heats of the composites prepared with raw and pyrolyzed fibers cured for $180 \mathrm{~d}$, placed in the curing chamber and water at $23^{\circ} \mathrm{C}$, are shown in Table 5 .

The lowest specific heats are noted for the composites cured in the curing chamber. They are of the same order of magnitude: $1 \cdot 12 \mathrm{~J} /(\mathrm{g} \mathrm{K})$ for $2 \%$ and $6 \%$ by mass of fibers, for either raw or pyrolyzed. For mortar composites having 1.5 and $3 \mathrm{wt} \%$ of pyrolyzed bagasse fibers, Onésippe et $a l^{32}$ found 0.5 and $0 \cdot 45 \mathrm{~J} /(\mathrm{g} \mathrm{K})$ for composites containing silica fume. Those values proposed by Onésippe et $a l^{32}$ are largely lower than the ones measured here, probably because of the chemical composition and the size distribution of the added materials (sand, calcium carbonate, bentonite, cellulose pulp, acrylic styrene polymer and silica fume).

After $180 \mathrm{~d}$ of curing, the amount of fibers and the pyrolysis of fibers do not influence the specific heat of ternary composites, either in the curing chamber or in water at $23^{\circ} \mathrm{C}$. The composites aged in the curing chamber present the lowest specific heat; they store less heat than others. The specific heats of the composites placed in the curing chamber, after $180 \mathrm{~d}$ of curing, are of the same order of magnitude as the CLA matrix without fiber after $28 \mathrm{~d}$, which is equal to $1 \cdot 12 \mathrm{~J} /(\mathrm{g} \mathrm{K})$.

Rodier $^{30}$ has shown that the porosity accessible to water, although it increases with the amount of fibers, does not depend on

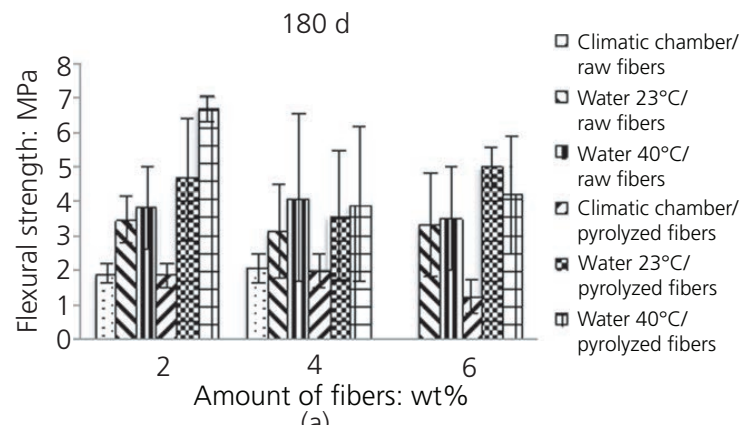

(a) the temperature of water; the porosities of the composites placed in water at $23^{\circ} \mathrm{C}$ and $40^{\circ} \mathrm{C}$ are similar. So the thermal conductivities of ternary composites are of the same order of magnitude as the specific heats in water, whatever the temperature.

In order to have thermal comfort in a house, taking into account thermal conductivity and specific heat, the more suitable material is prepared with the ternary matrix, $2 \%$ by mass of raw bagasse fibers and is used in internal walls not exposed to water.

\subsubsection{BENDING STRENGTH}

The flexural strengths of the materials, after 180 and $360 \mathrm{~d}$ of curing, are compared in Figure 6.

Whatever the age, taking into account the standard deviations, the flexural strengths of the composites cured in water, either at 23 or $40^{\circ} \mathrm{C}$, are similar; they are superior to those of the materials cured in the curing chamber. The flexural strengths slightly decrease with the duration of curing. Whatever the curing environment, the pyrolysis of fibers does not have a significant effect on the flexural strength. The highest strengths are noted for the composites cured in water, probably because the presence of external water favors the formation of $\mathrm{CSH}$ responsible for the mechanical properties of materials. ${ }^{30}$

In Figure 7, the typical bending strength against the specific deflection curves are observed. They show the contribution of the matrix in the elastic region until the first cracking phenomenon and after the reinforcing effect of the vegetable fiber, characterized by the transfer of forces from the matrix to the fibers that allows the ductile behavior in the composite.

\section{Conclusion}

Two ways of adding value to a local by-product, sugar cane bagasse, are proposed: ashes burnt at $600^{\circ} \mathrm{C}$ and particles in cementitious matrix. Cement without additives (20 wt \%) was partially replaced by BAs and NP to form a modified ternary matrix. Bagasse ( $2-6 \%$ by mass) was added to the ternary matrix in order to obtain insulating building materials as a replacement to asbestos. The thermal and mechanical properties of the resulting

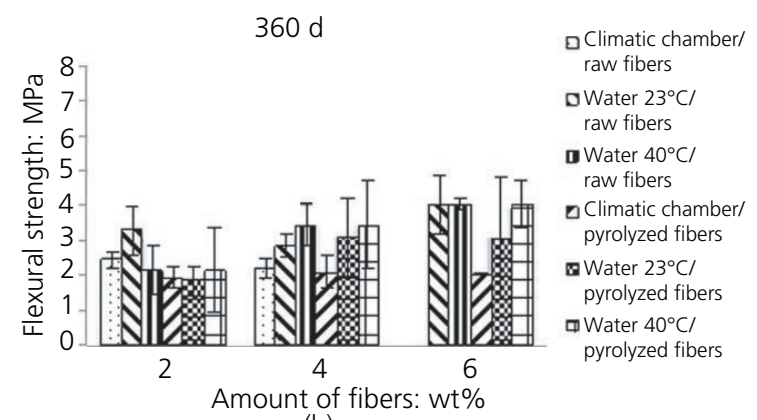

(b)

Figure 6. Bending strength of bagasse fibers/ternary composites placed in various environments after (a) 180 and (b) $360 \mathrm{~d}$ of curing 


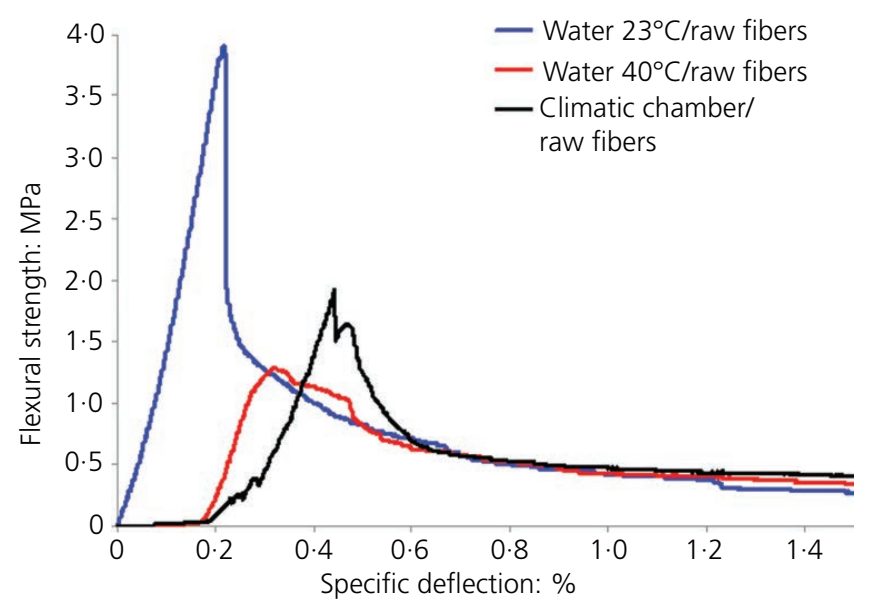

(a)

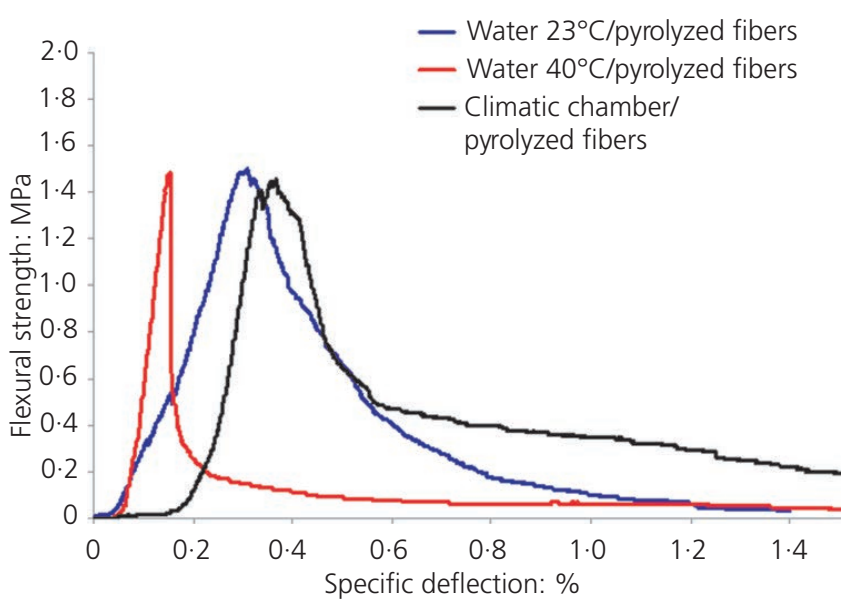

(b)

Figure 7. Bending strength of bagasse fibers/ternary composites placed in various environments after $180 \mathrm{~d}$ of curing (a) raw fibers (b) pyrolyzed fibers

composites were compared to those of the materials prepared with commercial cement.

When the materials are placed in the curing chamber for to $90 \mathrm{~d}$

- the ternary matrix produces better insulating composites than commercial cement, at $28 \mathrm{~d}$

- from a mechanical point of view, the fibers degrade the bending strength of the composites, no matter the treatment of the fibers and no matter the binder.

The study of the influence of three environments (curing chamber, water at 23 and $40^{\circ} \mathrm{C}$ ) on the thermal and flexural properties of the composite materials shows that

- when samples are placed in water, the thermal properties of the composites made with ternary matrix decrease, probably because water refines the porosity

- from a bending point of view, curing in water favors high flexural strengths.

Competitive as partial replacement of cement (CEM I) and performing as insulating components, ternary binder composites could be considered instead of CLA-based composites for the preparation of composite materials such as insulating mortars and concretes, especially for indoor applications in buildings.

\section{Acknowledgements}

The financial support from the Région Guadeloupe and the European funds for the projects Valorisation de la biomasse par l'élaboration de matériaux destinés aux traitements de dépollution de l'environnement et à l'éco-construction (numbers 30858 and 33622) and Développement d'isolants thermiques à partir de fibres végétales: ISOCFV (number 32524) and financial support from the Agence Nationale de la Recherche for the project AWaPUMat/Résidus industriels, leurs usages potentiels comme matériaux pour l'habitation et la construction (number ANR-12IS09-0002-01) are acknowledged.

\section{REFERENCES}

1. Fajardo G, Valdez P and Pacheco J (2009) Corrosion of steel rebar embedded in natural pozzolan based mortars exposed to chlorides. Construction and Building Materials 23(2): 768-774.

2. Núñez-Jaquez RE, Buelna-Rodríguez JE, Barrios-Durstewitz CP, Gaona-Tiburcio C and Almeraya-Calderón F (2012) Corrosion of modified concrete with sugar cane bagasse ash. International Journal of Corrosion 2012: 451864, http://dx. doi.org/10.1155/2012/451864.

3. Ganesan K, Rajagopal K and Thangavel K (2007) Evaluation of bagasse ash as supplementary cementitious material. Cement and Concrete Composites 29(6): 515-524.

4. Taylor HFW (ed.) (1997) Cement Chemistry, 2nd edn. Academic Press, London, UK.

5. Malhotra VM and Mehta PK (1996) Pozzolanic and Cementitious Materials. Taylor \& Francis. London, UK, Advances in Concrete Technology series, vol. 1.

6. RTAA DOM (2012) http://www.rt-batiment.fr/fileadmin/ documents/RTAA_DOM/rtaa_dom_protection_solaire dec2012.pdf (accessed 10/01/2013).

7. Citepa (Le Centre interprofessionnel technique d'études de la pollution atmosphérique) (2014) Inventaire des Emissions de Polluants Atmosphériques et de Gaz à Effet de Serre en Outre-mer - Analyse par Territoire. See http://www.citepa. org/fr/activites/inventaires-des-emissions/outre-mer (accessed 10/10/2014) (in French).

8. Khedari J, Suttisonk B, Pratinthong N and Hirunlabh J (2001) New lightweight composite construction materials with low 
Thermal and flexural properties of

bagasse/cement composites

Arsène, Bilba, Onésippe and Rodier thermal conductivity. Cement and Concrete Composites 23(1): $65-70$

9. Bilba K and Ouensanga (1996) A Fourier transform infrared spectroscopic study of thermal degradation of sugarcane bagasse. Journal of Analytical and Applied Pyrolysis 38: 61-73.

10. Cordeiro GC, Toledo Filho RD, Tavares LM and Fairbairn (2008) EM R Pozzolanic activity and filler effect of sugar cane bagasse ash in Portland cement and lime mortars. Cement and Concrete Composites 30(5): 410-418.

11. Arsène $M A$, Okwo $A$, Bilba $K$, Soboyejo $A B$ and Soboyejo WO (2007) Chemically and thermally treated vegetable fibers for reinforcement of cement-based composite. Materials and Manufacturing Processes 22(2): 214-227.

12. Normalisation Française des Ciments (2001) Norme NF EN 197-1: Méthodes d'essais des ciments - partie 1: détermination des résistances mécaniques. Normalisation Française des Ciments, La Plaine Saint-Denis, France (in French).

13. Savastano H, Warden PG and Coutts RSP (2000) Brazilian waste fibres as reinforcement for cement-based composites. Cement and Concrete Composites 22(5): 379-384.

14. ASTM (2009) ASTM C 948-81: Standard test method for dry and wet bulk density, water absorption and apparent porosity of thin sections of glass-fiber reinforced concrete. ASTM, West Conshohocken, PA, USA.

15. Normalisation Française des Ciments (2005) Norme NF EN 993-15: Méthodes d'essai pour produits réfractaires façonnés denses - partie 15: détermination de la conductivité thermique par la méthode du fil chaud (parallèle). Normalisation Française des Ciments, La Plaine Saint-Denis, France (in French).

16. Suliman ME and Almola SMF (2011) The use of sugarcane bagasse ash as an alternative local pozzolanic material: study of chemical compositioni. Science Vision 16-17: 65-70.

17. Day KW, Aldred J and Hudson B (2013) Concrete mix design. Quality Control and Specification, 4th edn. CRC Press Boca Raton, FL, USA.

18. ASTM (2008) ASTM C 618: Standard specification for coal fly ash and raw or calcined natural pozzolan for use in concrete. ASTM, West Conshohocken, PA, USA.

19. Cordeiro GC and Toledo Filho RD (2009) Effect of calcination temperature on the pozzolanic activity of sugar cane bagasse ash. Construction and Building Materials 23(10): 3301-3303.

20. Senhadji Y, Escadeillas G, Mouli G, Khelafi $H$ and Benosman AS (2014) Influence of natural pozzolan, silica fume and limestone fine on strength, acid resistance and microstructure of mortar. Powder Technology 254: 314-323.

21. Mouli M and Khelafi H (2008) Performance characteristics of lightweight aggregate concrete containing natural pozzolan. Building and Environment 43(1): 31-36.

22. Shannag MJ (2000) High strength concrete containing natural pozzolan and silica fume. Cement and Concrete Composites 22(12): 399-406.

23. Chusilp N, Jaturapitakkul C and Kiattikomol K (2009) Effects of LOI ground bagasse ash on the compressive strength and sulfate resistance of mortars. Construction and Building Materials 23: 3523-3531.

24. Tennis PD and Jennings HM (2000) A model for two types of calcium silicate hydrate in the microstructure of Portland cement pastes. Cement and Concrete Composites 30(6): 855-863.

25. Hamdan H, Mohd Muhid MN, Endud S, Listiorini E and Ramli Z (1997) Studies of rice husk silica for the synthesis of zeolites. Journal of Non-Crystalline Solids 211(1-2): 126-131.

26. Della VP, Kuhn I and Hotza D (2002) Rice husk ash: an alternate source for active silica production. Materials Letters 57(4): 818-821.

27. Zhang C, Aiqin W, Mingshu T and Xiaoyu L (1996) The filling role of pozzolanic material. Cement and Concrete Composites 26(6): 943-947.

28. Rodier L, Bilba $K$, Onésippe $C$ and and Arsène MA (2014) Sugar cane bagasse fibers/cement composites: influence of fiber content and thermal treatment of fibers on flexural strength. Proceedings of the International Conference on Computers in Education - 22, 13-19 July 2014, St-Julian,Malta.

29. Bejaoui S and Bary B (2007) Modeling of link between microstructure and effective diffusivity of cement pastes using a simplified composite model. Cement and Concrete Composites 37(3): 469-480.

30. Rodier L (2014) Matériaux de construction en zone tropicale humide - potentialités de sous-produits ou de matériaux naturels locaux en substitution ou addition à la matrice cimentaire. $\mathrm{PhD}$ thesis, Université des Antilles et de la Guyane, Pointe-a-Pitre, Guadeloupe (in French).

31. Benouis A, Grini A and Labrouki B (2008) Estimation de la porosité des bétons par ultrasons. Workshop Colloque National: Pathologie des Constructions - Du Diagnostic à la Reparation, 25-26 November 2008. University Mentouri Constantine, Constantine, Algeria (in French).

32. Onésippe C, Passecoutrin N, Toro F et al. (2010) Sugar cane bagasse fibers reinforced cement composites: thermal considerations. Composites: Part A 44(1): 549-556.

WHAT DO YOU THINK?

To discuss this paper, please submit up to 500 words to the managing editor at gmat@icepublishing.com.

Your contribution will be forwarded to the author(s) for a reply and, if considered appropriate by the editorin-chief, will be published as a discussion in a future issue of the journal.

ICE Science journals rely entirely on contributions sent in by professionals, academics and students coming from the field of materials science and engineering. Articles should be within 5000-7000 words long (short communications and opinion articles should be within 2000 words long), with adequate illustrations and references. To access our author guidelines and how to submit your paper, please refer to the journal website at www.icevirtuallibrary.com/gmat 